\title{
Anglicismo y tabú: valores axiológicos del anglicismo
}

Anglicism and taboo: axiological values of the pure anglicism

\author{
Eliecer Crespo-Fernández, ${ }^{1}$ Carmen Luján-García ${ }^{2}$
}

${ }^{1}$ Universidad de Castilla-La Mancha, Departamento de Filología Moderna, Albacete, España Correo electrónico: Eliecer.Crespo@uclm.es

${ }^{2}$ Universidad de Las Palmas de Gran Canaria, Departamento de Filología Moderna, Las Palmas de Gran

Canaria, España. Correo electrónico: clujan@dfm.ulpgc.es

La influencia del inglés en la lengua española en el ámbito del erotismo y la sexualidad ha dado lugar a un número considerable de anglicismos crudos para la designación de conceptos de la esfera sexual. Es el propósito de este trabajo examinar los valores axiológicos que el anglicismo presenta en el vocabulario sexual en el español europeo. Para ello, analizaremos los valores eufemísticos, disfemísticos y cuasieufemísticos que el anglicismo de naturaleza sexual presenta en un corpus léxico de anglicismos crudos extraídos del Diccionario gaylésbico (2008) y del Diccionario del sexo y el erotismo (2011). El análisis realizado demuestra que las voces anglicadas utilizadas en la esfera sexual no sólo buscan atenuar los tabúes lingüísticos, sino que también se usan para ofender y degradar e incluso para que un grupo social monopolice una serie de voces alusivas a conceptos vitandos.

Palabras clave: anglicismo crudo, tabú sexual, eufemismo, disfemismo, cuasieufemismo.

The influence of English on Spanish within the field of eroticism and sexuality has led to a considerable number of pure anglicisms to designate sex-related concepts. In this regard, it is the aim of this paper to examine the axiological values that anglicisms present in Spanish sexual vocabulary. To this end, we will explore the euphemistic, dysphemistic and quasieuphemistic values that sex-related anglicisms present in a corpus of pure anglicisms excerpted from two dictionaries: Diccionario gay-lésbico (2008) and Diccionario del sexo y el erotismo (2011). The analysis reveals that English borrowings do not only veil the so called linguistic taboos, but they are also used to disparage and degrade and even as a sign of cohesion within a group.

Key words: pure anglicism, sexual taboo, euphemism, dysphemism, quasieuphemism. 


\section{INTRODUCCIÓN}

Existen determinadas áreas de la lengua que están asociadas a lo tabú, ${ }^{1}$ a lo prohibido o, cuando menos, a lo políticamente incorrecto. Se podría afirmar que la esfera del erotismo y la sexualidad constituye uno de esos campos estigmatizados, plagado de términos y expresiones que pueden resultar groseros o malsonantes para los hablantes de cualquier sociedad, por abierta y liberal que sea. No en vano, pese a la mayor libertad y liberalización de costumbres experimentada en las últimas décadas, lo cierto es que el estigma que tradicionalmente ha recaído en el tabú sexual ha resistido a los efectos del paso del tiempo y sigue, en mayor o menor medida, vigente en las sociedades industrializadas del siglo xxı. Así, especialmente entre ciertos grupos sociales y en determinadas situaciones comunicativas, la inclusión de voces propias del terreno sexual sin la adecuada atenuación eufemística que permita su presentación, digamos, en sociedad, está vetada y pone en entredicho la imagen y el prestigio social del emisor (Crespo Fernández 2005).

De ello se deduce que existe una relación estrecha entre sociedad y lenguaje. No en vano, el tabú social conduce inevitablemente al tabú lingüístico como manifestación verbal de las prohibiciones que recaen sobre un individuo o grupo social. Como acertadamente señala Chamizo Domínguez, "es probable que donde mejor se pueda mostrar hasta qué punto el tabú sigue vivo en nuestra sociedad sea (...) en el lenguaje, es decir en lo que nos está y no nos está permitido decir" (2008: 32). Ante tal situación, los usuarios de una lengua recurren a una serie de mecanismos y estrategias verbales que les permitan abordar según su intención comunicativa (atenuación, ofensa, solidaridad de grupo, etc.) conceptos sujetos a interdicción. Y entre los recursos que para tales fines la lengua pone a disposición de los hablantes se encuentra el préstamo extranjero de origen anglosajón. Este estudio se centra precisamente en la relación entre el anglicismo y el tabú a través de sus principales manifestaciones en el plano verbal, a saber, el eufemismo, el cuasiuefemismo y el disfemismo.

Como es bien sabido, el inglés se ha convertido en la lingua franca o medio de comunicación más internacional, por lo que muchas sociedades occidentales están expuestas al tremendo influjo de la lengua inglesa. Varios volúmenes que han descrito el impacto del inglés en las lenguas europeas (Görlach 2002; Fischer y Pulaczewska 2008; Furiasi et al. 2012) señalan la importancia que el inglés tiene en la vida diaria de muchos europeos. España no es una excepción a esta influencia que se refleja de manera inequívoca en el idioma, como se ha demostrado en diferentes estudios académicos. Aunque algunos de estos trabajos abordan el anglicismo sintáctico (Rodríguez Medina 2002), la mayoría de los estudios relacionados con el anglicismo en el español europeo han explorado la huella del inglés en el nivel léxico, pues, como señala Medina López (1996: 20), se trata de la modalidad de anglicismo más perceptible y evidente. Así, no es de extrañar que el anglicismo léxico haya sido analizado en ámbitos tan dispares como la informática (Bolaños-Medina y LujánGarcía 2010), el deporte (Balteiro 2011) o la publicidad infantil (Luján-García 2011).

\footnotetext{
En esta investigación hay que distinguir entre los conceptos de tabú y tabú lingüístico. De acuerdo con Moreno Fernández (1998: 201), tabú es "la prohibición de ciertas acciones u objetos basada bien en razones religiosas, bien en otros prejuicios, convenciones o actitudes sociales", mientras que tabú lingüístico es "la palabra cuyo uso debe evitarse, generalmente por motivos sociales, políticos, sexuales o religiosos". Con respecto a la influencia del tabú en el plano lingüístico, léase Chamizo Domínguez (2008).
} 
Incluso áreas consideradas tabú, como la droga, han sido también objeto de estudio (Rodríguez González 1994).

Conviene distinguir entre diferentes tipos de anglicismos. Para ello seguimos a Lorenzo (1987), cuya clasificación es, nos atrevemos a decir, la más extendida y generalmente aceptada. Este autor distingue entre los siguientes tipos de anglicismos:

- Anglicismos crudos. Voces que mantienen en español la grafía inglesa y un reflejo de la pronunciación originaria más o menos fonético: cruising, escort o petting son algunos de los ejemplos presentes en nuestro corpus de estudio.

- Anglicismos en período de aclimatación. En estos anglicismos, unas veces la grafía y otras la pronunciación se han adaptado al español, por ejemplo bolliscout o chapear.

- Anglicismos totalmente asimilados. Términos que ya se han incorporado plenamente en la lengua española desde hace siglos bien directamente desde el inglés (chutar, túnel, suéter), bien a través del francés (norte, sur, babor).

- Calcos. Adaptaciones que se refieren a conceptos desconocidos por el que adapta, como rascacielos (skyscraper) o perro caliente (hot dog).

- Calcos semánticos. Voces españolas que, por su parecido formal con otras inglesas, reciben del inglés acepciones que no poseían en el español europeo como audiencia ('público') o romance ('amoríos').

En el presente trabajo nos limitaremos al análisis de anglicismos léxicos crudos. Por una parte, este tipo de anglicismo que, como hemos dicho, refleja de manera más evidente la huella del inglés, supone una fuente inagotable de creación léxica dentro del ámbito objeto de nuestro estudio, la sexualidad y el erotismo. Asimismo, este ámbito es proclive a la incorporación temporal de anglicismos crudos, voces que, en ocasiones, nunca llegan a integrarse totalmente en el español, forman parte de una moda pasajera y finalmente dejan de utilizarse. Hemos detectado otros tipos de anglicismos léxicos con una menor frecuencia en nuestro corpus, que constituirán el corpus de un estudio futuro.

El objetivo de este artículo es analizar los valores axiológicos ${ }^{2}$ que presenta el anglicismo crudo en la esfera del erotismo y la sexualidad en el español europeo. Concretamente, estudiaremos los valores eufemísticos, cuasieufemísticos y disfemísticos que se asocian al uso del anglicismo como recurso sustitutivo de voces interdictas y las motivaciones que impulsan al hablante a recurrir a voces anglicadas en referencia a conceptos sexuales. Un trabajo dedicado en exclusividad a los valores axiológicos del anglicismo sexual como el que aquí presentamos nos parece muy oportuno. De hecho, pese a que las voces de origen anglosajón no son, ni mucho menos, ajenas al ámbito de la sexualidad, lo cierto es que el valor axiológico del anglicismo en esta esfera de interdicción no ha recibido la atención que merece. En el mejor de los casos, la naturaleza eufemística de los préstamos de origen anglosajón en este campo ha formado parte de otros trabajos de orientación más generalista (Rodríguez González 1996 y 2008b; Gómez Capuz 2000: 110-114; y Rodríguez Medina 2003, entre otros).

Aplicada a la investigación lingüística, la axiología se refiere a los juicios valorativos (ya sean de signo positivo o negativo) de las unidades léxicas por los cuales estas se tiñen de afectividad. 
Este estudio consta de distintas partes. Después de presentar el corpus y la metodología seguida en el manejo de los datos, estableceremos la relación entre el anglicismo y las manifestaciones léxicas del tabú en el plano léxico. Posteriormente analizaremos los valores axiológicos del anglicismo presente en el corpus, para después presentar los resultados obtenidos y las conclusiones que se derivan de la investigación. Finalmente, ofrecemos un apéndice lexicográfico con los anglicismos crudos eufemísticos, disfemísticos y cuasieufemísticos extraídos del corpus.

\section{Corpus y Metodología}

El corpus en el que se basa esta investigación está compuesto por un total de 129 unidades léxicas que entran en la categoría del anglicismo crudo. Dadas las lógicas limitaciones de espacio, optamos por no incluir el análisis de otros tipos de anglicismos observados en el corpus, como los calcos y traducciones (bomba sexual, del inglés sex bomb), los pseudoanglicismos (hacerse un finger), las adaptaciones fonéticas o morfológicas (quin o toplesera) o las formaciones sigladas de origen anglosajón ( $L G B$ 'Lesbian. Gay. Bisexual'). Nos limitamos a los anglicismos crudos (bondage, stretching), la categoría más fácilmente identificable de anglicismos, como hemos apuntado en la introducción.

Las lexías anglicadas que componen el corpus han sido extraídas en su totalidad de dos diccionarios especializados de reciente aparición, ambos obra del lexicógrafo y sociolingüista Félix Rodríguez González: el Diccionario gay-lésbico (2008a, en adelante DGL) y el Diccionario del sexo y el erotismo (2011, en adelante DSE). La elección de estos diccionarios como corpus para la presente investigación no es fruto del azar. Ambos ofrecen un panorama completo y actualizado del campo semántico del sexo y el erotismo. No sólo por su considerable extensión (el DSE recoge más de 6200 voces y el DGL supera las 1500) y por su aparición relativamente reciente, sino también porque el autor huye de prejuicios en la recopilación de las voces, lo que supone la inclusión de lexías utilizadas para designar conceptos que, todavía en la sociedad del siglo xxi, están sujetos a una fuerte interdicción. Además, en su propósito de sistematizar el vocabulario sexual en un sentido amplio, Rodríguez González incluye diferentes registros de lengua, sin olvidar el componente oral del lenguaje sexual. Así, en ambos diccionarios conviven voces y expresiones de la lengua estándar, coloquialismos, regionalismos, tecnicismos y cultismos propios de la medicina o la sociología, amén de una gran cantidad de voces argóticas del ámbito de la prostitución, la pornografía, la homosexualidad o el sadomasoquismo. De ello se deduce que en estos diccionarios está asegurada la presencia de un corpus amplio, actualizado y representativo del uso y funciones del anglicismo en temas sexuales, una "ecografía" real de los usos lingüísticos actuales de las voces anglicadas dentro del ámbito objeto de nuestro análisis.

En estas obras hemos recopilado sistemáticamente los anglicismos crudos empleados en la designación de todo tipo de conceptos presentes en la esfera del erotismo y de la sexualidad, para después clasificarlos según las áreas temáticas en las que incide el anglicismo en cuestión. A fin de simplificar el tratamiento de los datos, nos hemos decantado por incluir aquellas voces susceptibles de aparecer en más de una categoría en aquélla a la que la voz en cuestión remita de manera más evidente. Así, por ejemplo, aunque fisting sea, en realidad, una práctica sexual, aparezca en el ámbito de la pornografía 
y se vincule al mundo homosexual (Rodríguez González 2008b: 259), la voz remite de manera más característica al sadomasoquismo, y en esta categoría la hemos incluido.

Posteriormente, hemos establecido la clasificación de las voces anglicadas según su valor axiológico, es decir, según su naturaleza eufemística, disfemística o cuasieufemística. Para ello, nos hemos remitido al contexto natural de aparición del anglicismo, que Rodríguez González aporta en sus diccionarios en la mayoría de las entradas, lo que contribuye sobremanera a comprender su uso real y coadyuva en la categorización de una lexía como eufemismo, disfemismo o cuasieufemismo. No en vano, dada la dependencia contextual de estos fenómenos, las etiquetas léxicas de atenuación, ofensa o cohesión grupal utilizadas en este trabajo no están consideradas aisladamente, sino dentro de su contexto de enunciación en el discurso, lo que les otorga su verdadera fuerza ilocutiva y permite descubrir las motivaciones y concepciones ideológicas subyacentes al uso del anglicismo crudo en la esfera sexual. No olvidemos, después de todo, como señalan Allan y Burridge (2006: 51), que las unidades léxicas no son eufemísticas o disfemísticas per se, sino que dependen del contexto en el que se utilizan y de las variables que afectan al acto comunicativo. Por ello, aunque una determinada palabra pueda actuar invariablemente como eufemismo, disfemismo o cuasieufemismo, el contexto nos aporta qué valor prima sobre los demás, que es el que hay que destacar en el análisis. Cabe señalar asimismo que hemos categorizado las unidades léxicas según su valor axiológico en sincronía, es decir, de acuerdo al valor que presentan en la actualidad sin atender por tanto al valor emotivo o connotativo que tenían en el pasado. Una vez presentado el corpus de estudio y la metodología seguida, y como paso previo al análisis del material léxico, conviene ofrecer unos apuntes sobre la relación existente entre el anglicismo y la materialización del tabú en el plano léxico.

La prohibición y el estigma que recaen sobre conceptos de naturaleza sexual no significa que estos hayan desaparecido de la lengua ni, por supuesto, de las mentes de sus usuarios. Del mismo modo que existe el tabú, existe en el plano de la lengua el tabú lingüístico, reflejo verbal de la interdicción conceptual y víctima de censura y prohibiciones. Sin embargo, y he aquí la gran paradoja del tema que nos ocupa, el tabú conceptual (especialmente el de índole sexual) es responsable de una gran cantidad de sustitutos léxicos. De hecho, lejos de eliminar el concepto tabú, el usuario de la lengua la aborda en sus dos extremos, ya sea mediante términos que huyan de la crudeza o grosería que transmite la voz vitanda o, por el contrario, a través de lexías que intensifiquen los matices menos aceptables, más ofensivos o groseros del referente en cuestión. El tabú, por tanto, genera esta doble vertiente, cuyas manifestaciones léxicas corresponden a los eufemismos, en el primer caso, y a los disfemismos, en el segundo.

De acuerdo con Casas Gómez (1999: 21), desde un punto de vista estrictamente lingüístico, los términos eufemísticos y disfemísticos son parasinónimos con respecto al tabú lingüístico al que sustituyen; es decir, entre el tabú verbal y la voz eufemística o disfemística se establece una similitud en sus significados, aunque nunca una identidad. Así, la variación léxica del eufemismo y del disfemismo da lugar a sinónimos parciales que actualizan únicamente aquellos rasgos de contenido más presentables y ofensivos respectivamente de los que forman parte de la referencia del concepto interdicto. En la connotación de los términos radica la diferencia entre ambos fenómenos: mientras que el eufemismo presenta connotaciones meliorativas o 
afectivamente positivas con respecto al término tabú al que sustituye, el disfemismo presenta connotaciones peyorativas o afectivamente negativas con respecto al término axiológicamente neutro al que reemplaza (Chamizo Domínguez 2008: 35). Así, el eufemismo y el disfemismo constituyen recursos antitéticos de manipulación del referente en el uso social del lenguaje al que recurren los hablantes, ya sea para intentar suavizar u ocultar sus rasgos menos aceptables o, por el contrario, para intensificarlos con ánimo normalmente ofensivo. Lógicamente, el referente no sufre alteración alguna en sí, aunque es manipulado por el emisor, en un sentido o en otro, y el resultado de esa manipulación es lo que el destinatario percibe.

De entre el amplio abanico de mecanismos que la lengua pone a disposición de sus usuarios para tales fines, tanto a nivel formal como a nivel de significado (CrespoFernández 2007: 119-117 y 179-183), se encuentra el recurso al préstamo extranjero, en nuestro caso el préstamo de origen anglosajón. Se trata de un mecanismo sustitutivo y de creación léxica que cumple diferentes funciones comunicativas. El anglicismo no se limita a sustituir una voz cargada negativamente por otra desprovista de esos matices ofensivos que pueda presentar el término patrimonial, y así disfrazar el concepto mediante un término foráneo que no ha sufrido el proceso de depreciación social del que ha sido víctima el término español. Es evidente que escort, voz anglicada para prostituta de lujo, no genera la reacción que su equivalente, prostituta, provoca, pese a ser un término en principio axiológicamente neutro, es decir, estrictamente referencial. La motivación del anglicismo no se limita a este uso eufemístico. Otras voces foráneas buscan deliberadamente explotar el estigma del tabú con un ánimo ofensivo. Es el caso de drag king kong, denominación jocosa utilizada para designar a una lesbiana de aspecto varonil que enfatiza los rasgos menos femeninos de la mujer por asociación con el famoso gorila King Kong. Por ello, se trata de una etiqueta léxica que posee connotaciones afectivamente negativas con respecto al término axiológicamente neutro al que sustituye, que no es otro que lesbiana.

Hay que dar también cuenta de otros anglicismos que se encuentran entre estos dos extremos. Voces propias del argot del sadomasoquismo incluidas en nuestro corpus de estudio como bondage 'ataduras', mistress 'ama' o squashing 'aplastamiento erótico’ persiguen, más que suavizar o mitigar el tabú, ocultar y monopolizar para un determinado grupo palabras y expresiones alusivas a conceptos propios de ese grupo; por ello, no se trata de eufemismos en un sentido estricto. Estas voces argóticas sirven como símbolo de identidad y de cohesión grupal en aquellas comunidades que comparten actividades y experiencias, en las que se favorece un lenguaje vernáculo un registro informal propio de la comunicación oral entre iguales-y que suelen ocultar el significado de sus referentes a fin de evitar el acceso de extraños. ${ }^{3}$ Las voces del argot sexual constituyen variaciones del fenómeno eufemístico que, desde el punto de vista de su relación con el tabú, se incluyen en la categoría axiológica del cuasieufemismo ${ }^{4}$ o disfemismo eufemístico en la terminología de Casas Gómez (1986).

En tanto las voces propias del ámbito sadomasoquista tienden a ocultar prácticas sexuales, aunque no ilegales, sí muy especiales, se podrían considerar casos de "antilenguaje", etiqueta que Halliday (1978: 171) propuso para el lenguaje utilizado por colectivos como los delincuentes o los consumidores de drogas.

$4 \quad$ Para un estudio detallado del cuasieufemismo como proceso mixto de manipulación del referente, sus variantes en el discurso y funciones pragmáticas, consúltese Crespo-Fernández (2007: 207-226). 
A continuación presentamos el análisis del corpus de anglicismos en la esfera sexual de acuerdo con los valores axiológicos que presentan las principales o, al menos, las voces anglicadas más representativas que sustituyen a los tabúes lingüísticos. Para ello, dividiremos nuestro análisis en las categorías apuntadas: eufemismos, disfemismos y cuasieufemismos.

\section{ANÁLisis DEL CORPUS}

\subsection{Anglicismos eufemísticos}

El recurso al préstamo extranjero de origen anglosajón constituye una fuente importante de creación eufemística en nuestro corpus. El carácter foráneo de las voces anglicadas resulta de suma utilidad para la sustitución de términos considerados obscenos o malsonantes en las diferentes categorías temáticas dentro del tabú sexual, como veremos a continuación.

Una parcela en la que el eufemismo adquiere un mayor protagonismo es la prostitución. De hecho, más de la mitad de los anglicismos detectados en esta categoría temática presenta una función atenuadora. El origen inglés de voces como playgirl, call-girl o escort disfraza el referente que designa al tiempo que pretende dignificar la imagen de la prostituta y elevar su estatus social mediante etiquetas léxicas alternativas, en las que la ambigüedad propia del eufemismo juega un papel fundamental. Digno de especial mención es el caso de escort, ${ }^{5}$ voz que se aplica tanto a la prostitución masculina como a la femenina. En sentido estricto designa a un acompañante, si bien, como consecuencia de un proceso de generalización semántica, ha pasado a designar al acompañante que ofrece sus servicios sexuales al cliente. Esta voz se aparta del lenguaje más ordinario o popular y pretende ennoblecer el concepto de prostituta al remitir a una prostitución de mayor categoría y, por tanto, destinada a personas con cierto poder adquisitivo, en un ambiente muy alejado del oscuro mundo de la prostitución callejera. Otros términos ingleses son también frecuentes en esta categoría temática como relax (voz genérica equivalente a prostitución) o blow job ('felación'). Además, la huella del inglés está presente en la designación de los lugares en los que tiene lugar el comercio carnal como love hotel, night club, sex club o soapland ('casa de masajes'). Todas estas voces anglicadas están muy alejadas de palabras como burdel o los disfemismos castizos casa de putas o puticlub, voces estigmatizadas y poco atractivas para los potenciales clientes. Un caso similar lo encontramos en la denominación de personas y oficios relacionados con el espectáculo del sexo tales como sexy girl, sexy boy, show girl o stripper. De ahí se deduce que estas voces, al igual que la ya comentada escort, cumplen, aparte de la función de dignificación social apuntada, una función estética, emparentada con el lenguaje publicitario, ya que, después de todo, el sexo es un negocio para muchas personas, y el eufemismo está al servicio del hablante interesado en hacer atractivo ese negocio mediante palabras que atraigan a clientes.

Como explica Rodríguez González en su DSE, estamos ante un anglicismo que presenta inconsistencia en su ortografía. La creencia errónea de que la ortografía original es scort (debido a la frecuencia de la -s líquida en inglés) ha dado lugar a variaciones grafemáticas entre scort y escort. 
Las prácticas y relaciones sexuales es otro campo fecundo para el uso eufemístico. Las etiquetas léxicas de origen anglosajón tienden a destacar los aspectos más inocentes de la relación y a ocultar los que evocan la dimensión puramente física de la misma; no en vano, para llevar a cabo su función mitigadora, el eufemismo subraya los rasgos más socialmente apropiados del concepto en cuestión, y el anglicismo eufemístico no es una excepción. Así, encontramos sustantivos compuestos con love como love affair o love story ('relación sexual') además de love-in ('orgía'), que destacan el componente amoroso del encuentro y encubren el sexual. Idéntico procedimiento aparece en el sintagma love hotel, apuntado en el párrafo anterior. A esta línea de vocablos "inocentes" también pertenece la expresión cheek to cheek, que remite en principio a un encuentro físico superficial. Cabe destacar dentro de esta categoría de eufemismos de relaciones íntimas o amorosas el caso de petting, voz derivada del verbo to pet que presenta el significado eufemístico de 'tocar o acariciar durante la relación’ y que tiene su origen en las caricias que se proporcionan a los animales domésticos (Holder 2003: 297). Contrariamente al uso que el término tiene en inglés, lengua en la que no se sólo se utiliza en el ámbito de la sexualidad, la palabra ha sido adoptada en el español europeo exclusivamente en un sentido sexual para designar cualquier tipo de relaciones sexuales a excepción del coito, incluidos besos y sexo oral. Aquí, junto al deseo de ocultación, en el uso de petting destaca la necesidad de cubrir un hueco en la designación de un concepto para el que no hay equivalente directo en español. Lo mismo se puede decir de vocablos como swinging ('intercambio de parejas'). En este tipo de anglicismos, al deseo de atenuación del concepto y de evitar voces malsonantes hay que añadir la necesidad de nombrar prácticas que, como tales, vienen importadas del mundo anglosajón.

La homosexualidad tanto masculina como femenina es otra categoría en la que el eufemismo tiene un papel destacado. El anglicismo más popular es gay, si bien este término carece de valor eufemístico en el español europeo actual, pues su uso se ha extendido y normalizado como término ortofemístico o referencial en la designación del homosexual masculino (curiosamente en inglés se emplea para ambos sexos). Gay convive con la voz homosexual en dicha designación y ambos términos se emplean prácticamente como sinónimos en el uso cotidiano. ${ }^{6}$ La altísima frecuencia de gay en el español actual da lugar a un buen número de compuestos con este término como el disfemismo rustic gay ('gay paleto') o el cuasiuefemismo gay line ('línea erótica para homosexuales').

Uno de los anglicismos por antonomasia dentro del campo de la homosexualidad está en el origen de la expresión, muy popular en el español europeo, salir del armario ('revelar la identidad homosexual'), traducción literal de la inglesa come out of the closet, que tiene su reflejo en el corpus en los anglicismos crudos come, coming out, out, outing y closet. Resulta curioso comprobar cómo en español no se ha documentado la expresión en su forma completa, que se ha tomado prestada en forma de calco, sino que son las palabras aisladas las que han pasado al español en forma

\footnotetext{
Pese a ello, lo cierto es que la connotación positiva de gay aporta al término un matiz diferente al de homosexual. Como explica Rodríguez González, esta connotación positiva del término gay explica "que en la literatura científica y especializada se reserve este término, homosexual, para designar al que experimenta atracción hacia personas del mismo sexo, sin más, y el de gay para el homosexual militante, que lucha en favor de la liberación sexual para acabar con la discriminación, haciendo de esa atracción su razón de ser y exigiendo a los demás que acepten su posicionamiento como medio para su reconocimiento personal" (2007: 114).
} 
de anglicismo crudo, lo que conlleva un mayor poder de ocultación del concepto. Lo mismo sucede en inglés, idioma en el que el sintagma verbal se ha abreviado para conseguir un efecto eufemístico más efectivo mediante el verbo come out, como señala Ayto (2007: 108). La expresión inglesa es también responsable del anglicismo inning, neologismo referido al hecho de mantener oculta la orientación homosexual. Aparte del componente eufemístico, en el uso de estos anglicismos se advierte un deseo de creatividad y originalidad en el uso de la lengua, incluso cierto esnobismo o afectación.

Aunque menos relevante desde el punto de vista cuantitativo, la homosexualidad femenina y el travestismo son parcelas igualmente receptoras de atenuación eufemística a través del anglicismo. Si bien algunas voces son compartidas por gays y lesbianas, hemos detectado tres entradas en nuestro corpus que aluden a la homosexualidad femenina eludiendo el vocablo directo y, por tanto, con valor eufemístico: girls crush ('atracción lésbica') y only for women and women only ('sólo para mujeres'). Con respecto al travestismo, Rodríguez González documenta dos voces emparentadas entre sí que cataloga como eufemismos: cross dressing ('travestismo') y cross dresser ('travestido'). Aunque se trata de términos propios del argot del travestismo, este lexicógrafo da cuenta de su uso en ensayos de antropología, por lo que nos hemos decantado por incluirlos en la categoría de eufemismos.

Para finalizar este breve repaso por el anglicismo eufemístico sexual nos detendremos en una voz digna de análisis: cock. Aunque en inglés es un término plenamente disfemístico en referencia al pene que ha generado un amplio abanico de sustitutos eufemísticos (Allan and Burridge 2006: 44-45), en su uso como anglicismo su valor axiológico cambia de manera radical. De hecho, Rodríguez González lo etiqueta como eufemismo en su DSE, después de comprobar su uso con valor de atenuación en el lenguaje literario. Igual sucede con el término dyke 'lesbiana', voz peyorativa en inglés y adoptada a modo de seña de identidad por el colectivo de lesbianas en su paso al español.

\subsection{Anglicismos disfemísticos}

En esta sección nos centraremos en el análisis de anglicismos crudos empleados con fines disfemísticos, o lo que es lo mismo, términos cargados negativamente, groseros o incluso insultantes. Al contrario de las voces eufemísticas, que buscan la atenuación a través del uso del anglicismo, las disfemísticas presentan connotaciones peyorativas o afectivamente negativas con respecto al tabú lingüístico al que sustituyen y tienden a intensificar los matices menos aceptables o más ofensivos del referente en cuestión.

Uno de las parcelas donde podemos observar el empleo de disfemismos con relativa frecuencia es el de la homosexualidad masculina. Hemos detectado en el corpus un amplio abanico de voces disfemísticas en la designación de estereotipos sexuales del mundo gay como rustic gay ('gay paleto') y teletubby ('gay adolescente'). Ambos vocablos poseen un indudable componente jocoso, lo que los convierte en voces aptas para el insulto y la descalificación. La naturaleza de la ofensa es, sin embargo, distinta en cada caso. Mientras que rustic gay explota el origen poco cultivado del homosexual, teletubby asocia la figura del homosexual joven a unos muñecos televisivos regordetes de apariencia cómica. Dentro de las denominaciones 
disfemísticas de estereotipos se encuentra también homofreak ('homosexual poco convencional'), un compuesto poco frecuente en el vocabulario homosexual que se puede considerar disfemismo dado el carácter ofensivo de freak ('raro, extraño'), voz que ha dado lugar a términos adaptados de carácter disfemístico en el español europeo como friki. Otros vocablos como chubby, que en inglés tiene el significado de 'gordito', se utiliza con un indudable tono humorístico y de burla en español para designar a un homosexual gordo y grande. De diferente cariz es el compuesto bug chaser ('buscador del bicho'), utilizado para referirse a esos homosexuales que mantienen relaciones sin protección con otros gays contagiados con el virus del SIDA. Esta lexía se refiere de forma frívola a un asunto tan serio como es una enfermedad que ha supuesto la muerte de miles de personas; de ahí la consideración de disfemismo de dicho compuesto.

La voz metafórica jet presenta una referencia jocosa al hombre homosexual, ya que evoca la imagen del avión reactor que se caracteriza por su propulsión trasera, con lo que la conexión con el sexo anal característico de las relaciones homosexuales entre hombres es obvio. La hipérbole que forma parte de la referencia del término coadyuva decisivamente en su naturaleza eufemística y en su evidente componente jocoso. No en vano, como señala Casas Gómez (1986), la metáfora es el mecanismo que mejor se adapta a la expresión del disfemismo, en tanto el lenguaje figurado tiende a intensificar el vocablo vitando provocando, de ese modo, la creación de imágenes de indudable poder ofensivo que, en casos como jet, cuentan además con un componente humorístico. La intensificación que caracteriza a la metáfora disfemística explica el hecho de que la hipérbole sea una constante en el disfemismo, como veremos a continuación en las referencias disfemísticas a las lesbianas.

Los compuestos con el adjetivo pink ('rosa') presentan un tipo diferente de referencia disfemística. Si bien pink es un término eufemístico que alude a la homosexual masculina debido a la simbología de este color (Rodríguez González 2007: 120), los compuestos pink power ('poder rosa') y más aún pink mafia ('mafia rosa') presentan connotaciones peyorativas en referencia al supuesto nepotismo que ejercen determinados personajes homosexuales en los campos de los medios de comunicación o la política. ${ }^{7}$

Los lugares asociados al mundo gay son también objeto de denominaciones disfemísticas. Es el caso de ghetto, término que designa un local donde se practica la homosexualidad y que cuenta con matices claramente despectivos por su asociación con el significado original del término ('zona poco recomendable').

En el campo de la homosexualidad femenina se observa también un amplio abanico de voces disfemísticas en referencia a los distintos estereotipos existentes. Para designar lesbianas extremadamente masculinas encontramos voces como super butch y stone butch. Cabe destacar que el término butch, pese a evocar la imagen masculina del carnicero, no se emplea con ánimo despectivo por el colectivo de lesbianas, que lo consideran como palabra propia de su comunidad y seña de identidad y, por tanto, entra en la categoría del cuasieufemismo, como veremos en el siguiente apartado. Son los intensificadores super y stone los que confieren un carácter ofensivo

Según Rodríguez González, en la primera época del movimiento de liberación homosexual, pink power también se refería a lesbianas, si bien es difícil afirmar este extremo pues el lesbianismo es más invisible que la homosexualidad masculina. Sin embargo, Rodríguez no tiene constancia de que pink mafia se haya referido en alguna ocasión a las lesbianas (comunicación personal). 
al nombre al que acompañan en los compuestos señalados. En esta línea cabe dar cuenta de vocablos como caterpillar, que asocia la imagen de la lesbiana a un camión o tractor Caterpillar, diseñado para circular por superficies difíciles e irregulares dada su potencia, o blackandecker, término empleado por su semejanza con el taladro de esta marca. En todas estas voces utilizadas en la designación de estereotipos de la homosexualidad femenina, el disfemismo presenta una naturaleza metafórica que se apoya en buena medida en las referencias hiperbólicas y que transmite la idea de la lesbiana como mujer fuerte mediante imágenes de potencia e incluso de agresividad. Voces metafóricas como éstas se pueden incluir en una metáfora conceptual como LA LESBIANA ES UNA MÁQUINA, según el modelo iniciado por Lakoff y Johnson (1980), de acuerdo con el cual la metáfora estructura nuestro sistema conceptual y ofrece, al mismo tiempo, una particular percepción del mundo que nos rodea. ${ }^{8}$

Las referencias disfemísticas no se limitan a la homosexualidad. La prostitución es un campo donde hemos encontrado términos como toyboy (o toy boy) para designar al hombre que mantiene relaciones sexuales con mujeres mayores que él, normalmente para conseguir un beneficio económico. Aquí, el disfemismo se apoya de nuevo en el lenguaje figurado, pues toyboy (literalmente 'chico de juguete') reduce al compañero sexual a un juguete en manos de la mujer en virtud de una conceptualización metafórica como El COMPAÑERO SEXUAL ES UN JUGUETE, que deshumaniza al individuo, lo reduce a un mero pasatiempo e indirectamente justifica todo tipo de comportamiento abusivo por parte de la mujer que disfruta de su compañía desde una posición de control y dominio absoluto sobre él.

Otra de las áreas temáticas incluidas en este trabajo es la de eventos y espectáculos. Aquí hemos recopilado voces disfemísticas como drag king kong ('drag queen muy corpulenta'), que hace referencia por volumen al gorila King Kong, con lo que el efecto jocoso es evidente. El componente humorístico lo encontramos también en un compuesto de naturaleza metafórica como joy stick ('pene erecto') dentro del área temática de los genitales.

En lo que se refiere a las prácticas y relaciones sexuales, varios términos derivados de dog 'perro' ponen de manifiesto la presencia del disfemismo. Las voces doggy style ‘posición sexual por la que la mujer se coloca en posición de un perro’ y dogging 'sexo al aire libre' reducen el intercambio sexual a su dimensión más primitiva al asociarlo a la actividad sexual de los perros. Con ello, indirectamente se deshumaniza la relación, que se limita a un intercambio físico carente de toda afectividad o sentimiento.

\subsection{Anglicismos cuasieufemísticos}

El cuasieufemismo es una variante del eufemismo que incluye voces que, más que mitigar el tabú, pretenden ocultar y monopolizar para un determinado grupo social palabras y expresiones alusivas a conceptos vitandos, como dijimos en el apartado 3. Son muchos los casos de unidades léxicas en nuestro corpus que mantienen ese tipo

\footnotetext{
No es nuestro propósito entrar en detalles sobre la Teoría de la Metáfora Conceptual, inicialmente propuesta por Lakoff y Johnson. Baste decir que en las metáforas conceptuales tiene lugar una proyección desde la imagen de la que nos servimos para la categorización metafórica $-\mathrm{o}$ dominio fuente- al concepto que queremos metaforizar $-\mathrm{o}$ dominio término-, y las asociaciones que constituyen esta metáfora configuran nuestra percepción y categorización del dominio término a partir de nuestra propia experiencia física o cultural.
} 
de relación con el tabú, ni de atenuación, ni de intensificación peyorativa, sino de símbolo de pertenencia a una comunidad. Por tanto, no es de extrañar que los casos de cuasieufemismo abunden en aquellas actividades que más se alejan de lo que se podría considerar estándar desde el punto de vista sexual; especialmente en las que durante décadas han estado prohibidas por las leyes españolas como la pornografía, la homosexualidad o la prostitución. En estas circunstancias resulta lógico que los miembros de un determinado grupo acuñen voces de carácter críptico que sirvan para ocultar el referente, como sucede en el mundo del sadomasoquismo, en el que el cuasieufemismo cuenta con una presencia abrumadora. Otras parcelas que favorecen un lenguaje exclusivo para designar conceptos alejados de prácticas sexuales consideradas estándar son los campos del travestismo y el de la transexualidad y la pornografía.

El sadomasoquismo constituye un caldo de cultivo para la referencia cuasieufemística al tabú a través de voces inglesas como fisting 'penetración con el puño', spanking 'azotes', tickling ‘cosquillas' o trampling 'aplastamiento erótico', entre otras. Igualmente los objetos relacionados con este ámbito han tomado prestado términos del inglés, como sucede con sling 'hamaca utilizada en prácticas sadomasoquistas'. Estas voces identifican a su usuario como iniciado, al menos, en el sadomasoquismo y resultan totalmente opacos para la persona ajena a ese mundo. En ocasiones el término inglés convive con el español en la designación del mismo concepto. Es el caso de ama y mistress 'mujer que ejerce el papel dominante', palabras que suelen aparecer indistintamente en los anuncios de prensa ofreciendo servicios sexuales sadomasoquistas. De hecho, el sadomasoquismo está muy relacionado con la prostitución, ámbito en cuyo argot también encontramos voces que delatan a su conocedor como usuario de estos servicios entre las que cabe señalar face 'eyaculación en la cara', body body 'masaje corporal erótico', rimming 'beso negro' o glory hole 'agujero por donde se introduce el pene para la práctica de felaciones y tocamientos'.

La huella del inglés se aprecia también en términos propios del ámbito del travestismo y la transexualidad como drag 'vestimenta propia de un sexo utilizada por el otro' y sus compuestos utilizados para designar estereotipos en el mundo del travestismo como drag queen 'hombre que se viste de mujer' y su antónimo, el menos frecuente drag king 'mujer que se viste de hombre'. Según el DGL, drag se utiliza también como abreviatura de drag queen, aunque este uso no se da en inglés, sino únicamente en el español europeo.

La influencia del inglés en forma de anglicismos crudos se observa igualmente en un ámbito cercano al travestismo, el de la homosexualidad masculina. En este campo, más de la mitad de los anglicismos con valor axiológico observados en nuestro corpus entran en la categoría del cuasieufemismo (concretamente 26 sobre 43), lo que da cuenta de la riqueza del argot homosexual. Así, las voces cuasieufemísticas son habituales en la designación de estereotipos del mundo homosexual, no solo del masculino sino también del femenino. Dentro del primer grupo cabe destacar por su frecuencia e influencia en el léxico el término queer. Como señala Rodríguez González en su DGL, después de considerarse primero un eufemismo y posteriormente una voz despectiva en la década de 1920, queer fue adoptado por los activistas gays para designarse a sí mismos; así, lógicamente, perdió su valor disfemístico y se convirtió en voz exclusiva de la comunidad homosexual, por tanto argótica y, desde el punto 
de vista de su relación con el tabú, cuasieufemística. ${ }^{9}$ Otros estereotipos de carácter más específico de origen anglosajón son bear 'homosexual peludo y gordo', chaser 'homosexual ávido de relaciones', daddy 'homosexual mayor, generalmente grueso' o leatherman 'homosexual aficionado al cuero'. De entre los anglicismos usados en la designación de estereotipos de la homosexualidad femenina el más habitual es butch 'lesbiana con rasgos viriles', voz que ha dado origen a los compuestos baby-butch 'butch joven' y butch party 'fiesta de lesbianas viriles', amén de otros de naturaleza disfemística del tipo de super butch o stone butch, según vimos en 4.2. En el otro extremo encontramos términos como lipstick 'lesbiana de rasgos femeninos'.

El anglicismo cuasieufemístico utilizado en el ámbito homosexual no se limita a la designación de estereotipos. Es también utilizado para designar prácticas propias del colectivo homosexual como cottaging o cruising 'ligoteo homosexual', ${ }^{10}$ barebacking 'penetración anal sin preservativo', docking 'masturbación mutua' o shaving 'afeitado erótico de la cabeza'. Igualmente se recurre al inglés para designar lugares relacionados con el mundo gay como cottage o cruising area en referencia a los lugares donde se practica cottaging y cruising respectivamente, dark room o black room 'sala oscura en determinados locales destinada a relaciones sexuales', village 'zona donde se sitúan locales de ambiente gay'. También se observan anglicismos en los nombres de eventos o celebraciones exclusivas de gays como tea-dance 'sesión de baile' y underwear party 'fiesta de ropa interior'.

La pornografía es otra de esas actividades que favorecen un lenguaje característico de la comunidad a la que pertenece y que se sirve del léxico inglés para designar conceptos alejados de prácticas sexuales consideradas estándar. De hecho, la mayoría de anglicismos del mundo de la pornografía observados en el corpus son susceptibles de ser incluidos en otras categorías como el sadomasoquismo o la pornografía (gangbang 'orgía entre un hombre y varias mujeres', fisting o fist fucking 'penetración con el puño', sandwich 'doble penetración', etc.). Asimismo, el ámbito de los objetos sexuales está muy próximo a estas áreas. Voces como cockring 'anillo que se sitúa en el pene' o strap-on 'consolador con arnés' hacen referencia a objetos utilizados en prácticas sexuales que se sitúan, podríamos decir, al margen de la norma.

No queremos terminar este apartado sin considerar un área temática de gran importancia para la sexualidad y el erotismo: la vestimenta. El vocabulario sexual toma prestado del inglés términos que supuestamente contribuyen a hacer más atractivo al compañero o más excitante el intercambio amoroso. Aunque muchos de los anglicismos observados en los diccionarios cumplen exclusivamente una función persuasiva o estética (babytop, bodysuit, miniskirt, etc.), sí podemos dar cuenta de algunos que constituyen una seña de identidad de un determinado colectivo, como el de la homosexualidad (leather 'cuero', chap 'pantalón corto de cuero') o la pornografía (grope suit 'especie de slip al que se añade un pene artificial').

9 El término queer es el origen de compuestos de origen anglosajón referentes a la cultura gay, como queer cinema, queer rock, queer studies, etc. Si bien queer se puede considerar una voz cuasieufemística, entendemos que sus compuestos suponen, más que una seña de identidad o la pertenencia a un colectivo, una especialización de registro al ser utilizados como anglicismos, razón por la cual no los hemos tratado en este estudio.

10 Aunque empleados aquí indistintamente, los términos cottaging y cruising presentan una diferencia de matiz que conviene señalar. Como indica Rodríguez González en su DGL, mientras que cruising designa el hecho de recorrer las calles en busca de una aventura homosexual, cottaging se refiere a la búsqueda de un compañero sexual en un lugar público, generalmente un urinario. 


\section{Resultados y CONCLUSIONES.}

A la vista de los resultados obtenidos, podemos afirmar que el uso de anglicismos en su forma cruda está muy presente en el lenguaje del erotismo y la sexualidad. Estos préstamos tomados del inglés son usados por los hablantes con diferentes fines que responden a los valores axiológicos de las voces anglicadas en el vocabulario sexual del español europeo, como resumiremos a continuación.

En primer lugar, el recurso al anglicismo crudo para atenuar los tabúes lingüísticos del ámbito sexual representa un total de 36 términos sobre los 129 que constituyen la totalidad de anglicismos del corpus (casi un 30\% de nuestra muestra). En segundo lugar, el uso de voces anglicadas de naturaleza sexual también está motivado por el deseo de ofender o degradar, es decir, el préstamo inglés intensifica los matices menos aceptables, más ofensivos o groseros del referente en un total de de 22 vocablos (alrededor de un 17\%). En tercer lugar, el anglicismo se utiliza para ocultar y monopolizar para un determinado grupo social palabras y expresiones alusivas a conceptos vitandos en un total de 71 voces (en torno al 55\%). El total de anglicismos crudos según su valor axiológico queda reflejado en la siguiente figura:

Figura 1

Valores axiológicos del anglicismo en el corpus

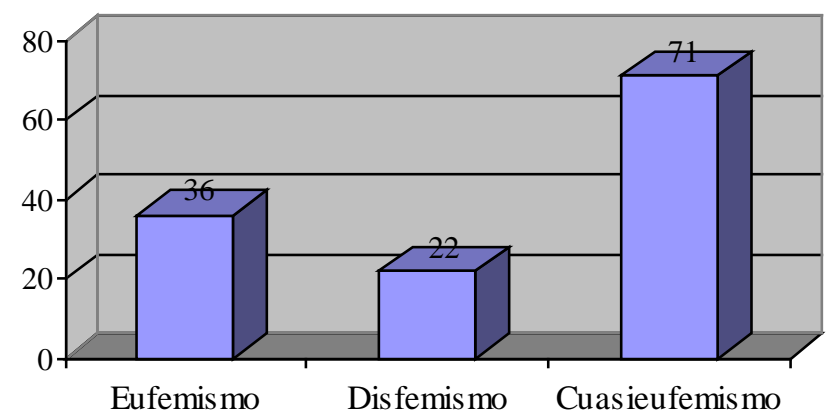

Resulta significativo el hecho de que el número de voces anglicadas con valor cuasieufemístico prácticamente duplique al de las voces eufemísticas y triplique al de las disfemísticas. De ahí se deduce que el valor axiológico dominante en el anglicismo crudo no sea ni la atenuación eufemística ni la ofensa disfemística, sino el uso de la palabra como signo de cohesión grupal propio del cuasieufemismo en la línea de las voces de argot.

En lo que respecta a los campos temáticos, en el presente estudio hemos detectado once áreas distintas dentro del anglicismo sexual que presentamos por orden alfabético en la siguiente tabla. Nótese que reflejamos las voces con valor eufemístico (columna marcada como EUF), disfemístico (DIS) y cuasieufemístico (CEF). 
Tabla 1

Principales categorías temáticas presentes en el corpus

\begin{tabular}{|l|c|c|c|c|}
\hline \multicolumn{1}{|c|}{ Áreas temáticas } & EUF & DIS & CEF & TOTAL \\
\hline Eventos y espectáculos & 2 & - & 2 & 4 \\
\hline Estereotipos sexuales & 1 & 1 & - & 2 \\
\hline Genitales & 1 & 2 & - & 3 \\
\hline Homosexualidad masculina & 8 & 9 & 26 & 43 \\
\hline Homosexualidad femenina & 3 & 6 & 5 & 14 \\
\hline Pornografía & 1 & - & 2 & 3 \\
\hline Prácticas y relaciones sexuales & 8 & 2 & 9 & 19 \\
\hline Prostitución & 10 & 2 & 6 & 18 \\
\hline Sadomasoquismo & - & - & 10 & 10 \\
\hline Travestismo / Transexualidad & 2 & - & 4 & 6 \\
\hline Vestimenta / objetos & - & - & 7 & 7 \\
\hline TOTAL & $\mathbf{3 6}$ & $\mathbf{2 2}$ & $\mathbf{7 1}$ & $\mathbf{1 2 9}$ \\
\hline
\end{tabular}

Como se aprecia en la tabla, de las categorías temáticas existentes la homosexualidad masculina resulta especialmente prolífica en cuanto al número de anglicismos utilizados (43 voces distintas). A cierta distancia encontramos las áreas de prácticas y relaciones sexuales (19), prostitución (18), homosexualidad femenina (14) y sadomasoquismo (10). Ya con escasa relevancia cuantitativa encontramos otras categorías como la vestimenta y los objetos sexuales (7) y el travestismo y la transexualidad (6). Con apenas representación en nuestro corpus se hallan las categorías de eventos y espectáculos (4), pornografía (3), genitales (3) y estereotipos sexuales (2).

Es interesante señalar que en aquellas áreas temáticas que se corresponden con actividades sexuales al margen de la norma domina el valor axiológico cuasieufemístico, que se sirve del inglés para monopolizar para un determinado grupo conceptos relativos al sadomasoquismo (en un 100\% de los anglicismos observados en esta categoría), a la pornografía y al travestismo/transexualidad (alrededor del $66 \%$ en ambos casos). Muchas voces incluidas en otras categorías como las de la vestimenta y los objetos sexuales así como la de prácticas y relaciones sexuales están estrechamente relacionadas con esas otras áreas un tanto al margen de las prácticas sexuales consideradas estándar. Es también digno de mención el hecho de que el número mayor de anglicismos eufemísticos se observe en el área de la prostitución, lo que responde a un deseo de ennoblecer esa actividad y hacer la figura de la prostituta más atractiva para el asiduo a estos servicios; no en vano, el sexo es un negocio para muchas personas, y el anglicismo eufemístico contribuye a atraer a potenciales clientes. Por el contrario, el disfemismo destaca cuantitativamente en la designación del hombre y la mujer homosexual, lo que demuestra que los prejuicios sexuales y la homofobia siguen desgraciadamente vigentes en la sociedad española.

Por otra parte, resulta interesante observar cómo los hablantes hacen un uso no aislado de anglicismos dentro de la esfera del erotismo y la sexualidad. De hecho, además de los valores axiológicos que el anglicismo sexual presenta, en el empleo de 
algunos de estos vocablos se advierte cierto sesgo esnobista y de mera pedantería, ya que existen equivalentes en español que designan el mismo concepto que el anglicismo. Es el caso de voces como doggy style o gay line, que cuentan con etiquetas léxicas tan válidas como a cuatro patas o línea gay respectivamente. Por ello, Alcaraz Varó y Martínez Linares (1997: 530) denominaron, de manera harto significativa, este tipo de anglicismos "préstamos de lujo", frente a los "préstamos de necesidad", es decir, aquellos que no cuentan con un equivalente directo en la lengua receptora, razón por la cual vienen a cubrir un vacío lingüístico, lo que sucede, por ejemplo, con cruising 'ligoteo homosexual' o swinging 'intercambio de parejas'. Debemos tener en cuenta, además, que muchos de estos conceptos provienen del mundo anglo-americano, lo que hace que prácticas nacidas en Estados Unidos o el Reino Unido como las citadas tengan denominaciones en inglés en el español europeo. De este modo, el anglicismo enriquece el sistema léxico-semántico del español, puesto que ni el significante ni, en ocasiones, el significado de esas voces existían antes en este idioma.

En suma, el anglicismo en la esfera del erotismo y la sexualidad presenta valores axiológicos de atenuación, intensificación u ocultación del tabú en los que inciden una serie de factores sociales que tienen un peso incuestionable en la opción por una voz anglicada en lugar del término patrimonial; al mismo tiempo, el uso del préstamo inglés refleja inequívocamente los valores y prejuicios de la sociedad receptora con respecto al tabú.

\section{APÉNDICE LEXICOGRÁFICO}

El glosario que sigue presenta los anglicismos encontrados en los dos diccionarios que constituyen el corpus para el presente trabajo. Junto al significado o equivalente en el español europeo, se incluye la categoría temática a la que pertenece la voz anglicada y su valor axiológico como eufemismo, disfemismo o cuasieufemismo.

Baby-butch. Butch joven. Homosexualidad femenina. Cuasieufemismo.

Bamboning. Striptease masculino. Homosexualidad masculina. Cuasieufemismo.

Barebacking. Penetración anal sin preservativo. Homosexualidad masculina. Cuasieufemismo.

Bear. Homosexual peludo y gordo. Homosexualidad masculina. Cuasieufemismo.

Bear chaser. Cazador de osos. Homosexualidad masculina. Cuasieufemismo.

Bisex. Bisexual. Prácticas y relaciones sexuales. Cuasieufemismo.

Black room. Sala oscura en determinados locales destinada a relaciones sexuales. Homosexualidad masculina. Cuasieufemismo.

Blackandecker. Lesbiana muy viril. Homosexualidad femenina. Disfemismo. Blow job. Felación. Prácticas y relaciones sexuales. Eufemismo. Body. Mujer atractiva. Estereotipos. Disfemismo.

Body (to) body. Masaje corporal erótico. Prostitución. Cuasieufemismo.

Body massage. Masaje corporal erótico. Prostitución. Cuasieufemismo.

Bondage. Ataduras. Sadomasoquismo. Cuasieufemismo.

Bottom. Homosexual pasivo. Homosexualidad masculina. Cuasieufemismo.

Bug chaser. Homosexual masculino que busca el contagio del SIDA. 
Homosexualidad masculina.

Disfemismo.

Butch. Lesbiana viril. Homosexualidad femenina. Cuasieufemismo.

Butch party. Fiesta de lesbianas viriles.

Homosexualidad femenina.

Cuasieufemismo.

Butt plugs. Juguetes sexuales.

Vestimenta y objetos. Cuasieufemismo.

Call-girl. Prostituta que se cita por teléfono. Prostitución. Eufemismo.

Camp. Amanerado. Homosexualidad masculina. Cuasieufemismo.

Caterpillar. Lesbiana muy viril.

Homosexualidad femenina. Disfemismo.

Chap. Pantalón corto de cuero.

Vestimenta y objetos. Cuasieufemismo.

Chaser. Homosexual ávido de

relaciones. Homosexualidad masculina.

Cuasieufemismo.

Cheek to cheek. Acto de juntar las mejillas como gesto amoroso. Prácticas y relaciones sexuales y amorosas. Eufemismo.

Chubby. Homosexual gordo y grande. Homosexualidad masculina.

Disfemismo.

Closet. Salir del armario.

Homosexualidad masculina. Eufemismo.

Cock. Pene. Genitales. Eufemismo.

Cockring. Anillo que se pone en el pene.

Vestimenta y objetos. Cuasieufemismo.

Come. Salir del armario.

Homosexualidad masculina. Eufemismo.

Come out of the closet. Salir del

armario. Homosexualidad masculina.

Eufemismo.

Coming out. Salir del armario.

Homosexualidad masculina. Eufemismo.

Cottaging. Ligoteo con fines

homosexuales. Homosexualidad

masculina. Cuasieufemismo.

Cross dresser. Travestido. Travestismo y

transexualidad. Eufemismo.

Cross dressing. Travestismo.

Travestismo y transexualidad.

Eufemismo.

Cruising. Ligoteo homosexual.
Homosexualidad masculina.

Cuasieufemismo.

Cruising area. Lugar donde se practica

el cruising. Homosexualidad masculina.

Cuasieufemismo.

Cub. Bear joven. Homosexualidad masculina. Cuasieufemismo.

Daddy. Homosexual mayor, generalmente grueso. Homosexualidad masculina. Cuasieufemismo.

Dark room. Sala oscura en determinados locales destinada a relaciones sexuales. Homosexualidad masculina. Cuasieufemismo.

Docking. Masturbación mutua. Prácticas y relaciones sexuales. Cuasieufemismo.

Dogging. Sexo al aire libre. Prácticas y relaciones sexuales. Disfemismo.

Doggy style. Posición a cuatro patas.

Prácticas y relaciones sexuales.

Disfemismo.

Drag. Vestimenta propia de un sexo utilizado por otro. Travestismo y transexualidad. Cuasieufemismo.

Drag king. Mujer travestida.

Travestismo y transexualidad.

Cuasieufemismo.

Drag queen. Hombre travestido.

Travestismo y transexualidad.

Cuasieufemismo.

Drag king kong. Drag queen muy corpulenta. Homosexualidad femenina.

Disfemismo.

Dress code. Código de vestimenta.

Vestimenta y objetos. Cuasieufemismo.

Dyke. Lesbiana. Homosexualidad femenina. Cuasieufemismo.

Escort. Mujer u hombre que se prostituye a alto nivel. Prostitución.

Eufemismo.

Face. Eyaculación en la cara.

Prostitución. Cuasieufemismo.

Fany. Órgano genital femenino y prostituta. Genitales y prostitución.

Disfemismo.

Fast sex. Relación sexual rápida.

Prácticas y relaciones sexuales. 
Cuasieufemismo.

Felching. Práctica sexual. Prácticas y relaciones sexuales. Cuasieufemismo. Fetish. Excitación sexual. Prácticas y relaciones sexuales. Cuasieufemismo. Fist fucking. Penetración con el puño. Sadomasoquismo. Cuasieufemismo.

Fisting. Penetración con el puño. Sadomasoquismo. Cuasieufemismo. Gang-bang. Orgía entre un hombre y varias mujeres. Prácticas y relaciones sexuales. Eufemismo.

Gay friendly. Comprensión hacia los gays. Homosexualidad masculina. Cuasieufemismo.

Gay line. Línea telefónica de gays. Homosexualidad masculina. Cuasieufemismo.

Gay movie. Película de gays. Homosexualidad masculina. Cuasieufemismo.

Gay side. Zona de ambiente. Homosexualidad masculina. Cuasieufemismo.

Ghetto. Lugar para la práctica homosexual. Homosexualidad masculina. Disfemismo.

Girls crush. Atracción lésbica. Lesbianismo. Eufemismo.

Glory hole. Agujero por donde se introduce el pene para la práctica de felaciones y tocamientos. Prostitución. Cuasieufemismo.

Grope suit. Slip al que se añade un pene artificial. Vestimenta y objetos. Cuasieufemismo.

Homofreak. Homosexual excéntrico. Homosexualidad masculina.

Disfemismo.

Inning. Ocultar la homosexualidad. Homosexualidad masculina. Eufemismo. Jet. Homosexual. Homosexualidad masculina. Disfemismo.

Joy stick. Pene erecto. Genitales. Disfemismo.

King. Mujer travestida. Travestismo y transexualidad. Cuasieufemismo.
Lap dance. Baile sexual. Eventos y espectáculos. Cuasieufemismo.

Leather. Cuero característico de algunos homosexuales, sobre todo sadomasoquistas. Vestimenta y objetos. Cuasieufemismo.

Leatherman. Homosexual aficionado al cuero. Homosexualidad masculina. Cuasieufemismo.

Lipstick. Lesbiana de rasgos femeninos. Homosexualidad femenina. Cuasieufemismo.

Love affair. Romance o relación pasajera. Prácticas y relaciones sexuales y amorosas. Eufemismo.

Love hotel. Hotel para relaciones sexuales esporádicas. Prostitución. Eufemismo.

Love-in. Orgía. Prácticas y relaciones sexuales. Eufemismo.

Love story. Historia de amor. Prácticas y relaciones sexuales y amorosas.

Eufemismo.

Mami blue. Tipo de felación. Prostitución. Cuasieufemismo.

Mistress. Mujer que adopta papel dominante en prácticas sadomasoquistas. Sadomasoquismo. Cuasieufemismo.

Night club. Club de alterne o prostíbulo. Prostitución. Eufemismo.

Only (for) Women. Relativo al lesbianismo. Homosexualidad femenina. Eufemismo.

Outing. Salir del armario. Homosexualidad masculina. Eufemismo. Petting. Relación sexual en la que no se llega al coito. Prácticas y relaciones sexuales. Eufemismo.

Pink. Relativo a la homosexualidad. Homosexualidad masculina. Eufemismo.

Pink mafia. Poder rosa.

Homosexualidad masculina.

Disfemismo.

Pink power. Mafia rosa.

Homosexualidad masculina.

Disfemismo.

Playgirl. Prostituta de alto nivel. 
Prostitución. Eufemismo.

Playroom. Sala donde se practica sexo en grupo. Prácticas y relaciones sexuales. Cuasieufemismo.

Power finger. Lesbiana.

Homosexualidad femenina. Disfemismo. Queen. Homosexual mayor afeminado. Homosexualidad masculina.

Cuasieufemismo.

Queer. Homosexual. Homosexualidad masculina. Cuasieufemismo.

Rainbow. Relativo a la homosexualidad. Homosexualidad masculina y femenina. Cuasieufemismo.

Relax. Servicio de prostitución.

Prostitución. Eufemismo.

Rimming. Beso negro. Prostitución.

Cuasieufemismo.

Rubbing. Estimulación vaginal.

Prácticas y relaciones sexuales.

Cuasieufemismo.

Rustic gay. Gay de aspecto tosco.

Homosexualidad masculina.

Disfemismo.

Sandwich. Doble penetración.

Pornografía. Cuasieufemismo.

Sex appeal. Apariencia atractiva y sexy.

Estereotipos sexuales. Eufemismo.

Sex club. Club de alterne. Prostitución.

Eufemismo.

Shaving. Práctica sexual.

Homosexualidad masculina.

Cuasieufemismo.

Sling. Hamaca utilizada en prácticas sadomasoquistas. Sadomasoquismo.

Cuasieufemismo.

Snowballing. Intercambio de semen.

Prácticas y relaciones sexuales.

Cuasieufemismo.

Soapland. Casa de masajes.

Prostitución. Eufemismo.

Soft / Soft-core. Pornografía blanda. Pornografía. Cuasieufemismo.

Spank / Spanking. Azotes.

Sadomasoquismo. Cuasieufemismo.

Squashing. Aplastamiento erótico.

Sadomasoquismo. Cuasieufemismo.
Squeezing. Práctica sexual. Prácticas y relaciones sexuales. Cuasieufemismo.

Stone butch. Lesbiana muy masculina. Homosexualidad femenina. Disfemismo. Straight. Heterosexual. Homosexualidad masculina. Cuasieufemismo.

Strap-on. Consolador con arnés. Vestimenta y objetos. Cuasieufemismo.

Stretching. Excitación por prendas ajustadas. Vestimenta y objetos. Cuasieufemismo.

Super butch. Lesbiana muy masculina. Homosexualidad femenina. Disfemismo Swinger. Persona que practica el swinging. Prácticas y relaciones sexuales. Eufemismo.

Swinging. Intercambio de parejas. Prácticas y relaciones sexuales. Eufemismo.

Table girl. Bailarina erótica. Eventos y espectáculos. Eufemismo.

Taxi girl. Mujer acompañante en sala de fiestas. Eventos y espectáculos. Eufemismo.

Tea-dance. Sesión de baile gay. Eventos y espectáculos. Cuasieufemismo.

Teletubby. Gay adolescente.

Homosexualidad masculina.

Disfemismo.

Tickling. Hacer cosquillas.

Sadomasoquismo. Cuasieufemismo.

Toyboy / Toy boy. Prostituto.

Prostitución. Disfemismo.

Trampling. Aplastamiento.

Sadomasoquismo. Cuasieufemismo.

Underwear party. Fiesta de ropa

interior. Homosexualidad masculina.

Cuasieufemismo.

Village. Barrio gay. Homosexualidad masculina. Cuasieufemismo.

Women Only. Relativo al lesbianismo. Homosexualidad femenina. Eufemismo. Wilde. Relativo a la homosexualidad. Homosexualidad masculina. Eufemismo. Wraping. Práctica de envolver a una persona. Sadomasoquismo. Cuasieufemismo. 


\section{Agradecimientos}

Vaya nuestro agradecimiento al Dr. Félix Rodríguez González por su ayuda en la realización de este estudio.

\section{OBRAS CITADAS}

Alcaraz Varó, Enrique y María Antonia Martínez Linares. 1997. Diccionario de lingüística moderna. Barcelona: Ariel.

Allan, Keith y Kate Burridge. 2006. Forbidden Words. Taboo and the Censoring of Language. Cambridge: Cambridge University Press.

Ayto, John. 2007. Wobbly Bits and other Euphemisms. Londres: A\&C Black.

Balteiro, Isabel. 2011. "A reassessment of traditional lexicographical tools in the light of new corpora: sports anglicisms in Spanish”. International Journal of English Studies 11.2: 23-52.

Bolaños-Medina, Alicia y Carmen Luján-García. 2010. "Análisis de los anglicismos informáticos crudos del léxico disponible de los estudiantes universitarios de traducción". Lexis 34.2: 241-274.

Casas Gómez, Miguel. 1986. La interdicción lingüística. Mecanismos del eufemismo y disfemismo. Cádiz: Universidad. 1999. Las relaciones léxicas. Tubinga: Niemeyer.

Chamizo Domínguez, Pedro. 2008. “Tabú y lenguaje: Las palabras vitandas y la censura lingüística". Thémata. Revista de Filosofía 40: 31-46.

Crespo-Fernández, Eliecer. 2005. "Euphemistic strategies in politeness and face concerns". Pragmalingüística 13: 77-86.

2007. El eufemismo y el disfemismo. Alicante: Universidad.

Fischer, Roswitha y Hannah Pulaczewska, eds. 2008. Anglicisms in Europe. Linguistic Diversity in a Global Context. Newcastle upon Tyne: Cambridge Scholars.

Furiasi, Cristiano, Virginia Pulcini y Félix Rodríguez González, eds. 2012. The Anglization of European Lexis. Ámsterdam y Filadelfia: John Benjamins.

Gómez Capuz, Juan. 2000. Anglicismos léxicos en el español coloquial. Cádiz: Universidad.

Görlach, Manfred, ed. 2002. English in Europe. Oxford: Oxford University Press.

Halliday, Michael A.K. 1978. Language as a Social Semiotic. Londres: Edward Arnold.

Holder, R. W. 2003. Dictionary of Euphemisms. How not to Say what you Mean. Oxford: Oxford University Press.

Lakoff, George y Mark Johnson. 1980. Metaphors We Live By. Chicago: The University of Chicago Press.

Lorenzo, Emilio. 1987. "Anglicismos en la prensa”. Primera reunión de Academias de la Lengua Española sobre el lenguaje y los medios de comunicación. Madrid: RAE. 71-79.

Luján-García, Carmen. 2011. “English invasion’ in Spain: An analysis of toys leaflets addressed to young children". English Today 27.1: 3-9.

Medina López, Javier. 1996. El anglicismo en el español actual. Madrid: Arco.

Moreno Fernández, Francisco. 1998. Principios de sociolingüística y sociología del lenguaje. Barcelona: Ariel.

Rodríguez González, Félix. 1994. "Anglicismos en el argot de la droga”. Atlantis 16.1: 179-216. . 1996. "Functions of anglicisms in contemporary Spanish", Cahiers de lexicologie 68.1: 107-128.

.2007. "Estereotipos y términos de caracterización homosexual". Cultura, homosexualidad y homofobia. Ed. Félix Rodríguez González. Barcelona: Laertes. 2008a. Diccionario gay-lésbico. Madrid: Gredos. . 2008b. "Anglicisms in Spanish male homosexual terminology". Anglicisms in Europe. 
Eds. Roswitha Fischer y Hannah Pulaczewska. Newcastle: Cambridge Scholars. 247-273. 2011. Diccionario del sexo y el erotismo. Madrid: Alianza.

Rodríguez Medina, María J. 2002. "Los anglicismos de frecuencia sintácticos en español". RESLA 15: 149-170. 2003. "La presencia del inglés en España. Antecedentes y panorama actual". Analecta Malacitana 13. http://www.anmal.uma.es/numero13/Medina.htm 
